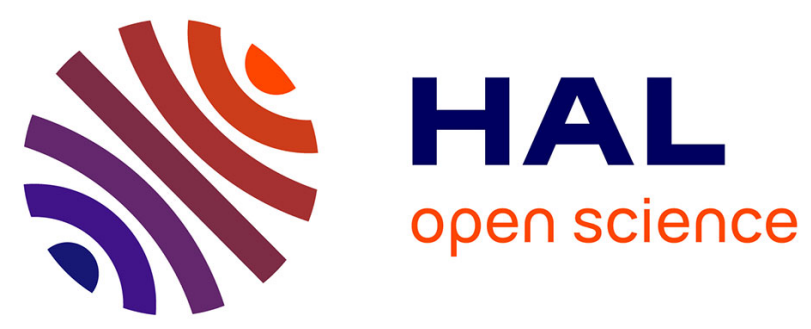

\title{
Experimental atomic scale investigation of irradiation effects in CW 316SS and UFG-CW 316SS
}

\author{
Philippe Pareige, Auriane Etienne, B. Radiguet
}

\section{To cite this version:}

Philippe Pareige, Auriane Etienne, B. Radiguet. Experimental atomic scale investigation of irradiation effects in CW 316SS and UFG-CW 316SS. Journal of Nuclear Materials, 2009, 389 (2), pp.259-264. 10.1016/j.jnucmat.2009.02.009 . hal-02107659

\section{HAL Id: hal-02107659 \\ https://hal.science/hal-02107659}

Submitted on 27 May 2020

HAL is a multi-disciplinary open access archive for the deposit and dissemination of scientific research documents, whether they are published or not. The documents may come from teaching and research institutions in France or abroad, or from public or private research centers.
L'archive ouverte pluridisciplinaire HAL, est destinée au dépôt et à la diffusion de documents scientifiques de niveau recherche, publiés ou non, émanant des établissements d'enseignement et de recherche français ou étrangers, des laboratoires publics ou privés. 


\title{
Experimental atomic scale investigation of irradiation effects in CW 316 SS and UFG-CW 316SS
}

\author{
P. Pareige *, A. Etienne, B. Radiguet \\ Groupe de Physique des Matériaux, ERT No.1000, Université et INSA de Rouen, UMR CNRS 6634, BP 12, 76801 Saint Etienne du Rouvray cedex, France
}

A R T I C L E I N F O

\section{PACS:}

$61.80 . \mathrm{Hg}$

61.82.Bg

68.37.Vj

28.41. $-\mathrm{i}$

64.75.Jk

81.07.-b

\begin{abstract}
A B S T R A C T
Materials of the core internals of pressurized water reactor (austenitic stainless steels) are subject to neutron irradiation. To understand the ageing mechanisms associated with irradiation and propose life predictions of components or develop new materials, irradiation damage needs to be experimentally investigated. Atomic scale investigation of a neutron-irradiated CW316 SS with the laser pulsed atom probe gives a detailed description of the solute segregation in the austenitic grains. In order to understand the mechanism of solute segregation detected in the neutron-irradiated materials, ion irradiations were performed. These latest irradiations were realized on a CW 316SS as well as on a nanostructured CW 316SS. The study of irradiation effects in a nanograin material allows first, to easily analyse grain boundary segregation and second, to test the behaviour under irradiation of a new nanostructured material. The three aspects of this atomic scale investigation (neutron irradiation effect, model ion irradiation, new nanostructured CW 316 SS) are tackled in this paper.
\end{abstract}

\section{Introduction}

The internal structures of pressurized water reactors (PWR) located close to the reactor core consist generally of baffle plates made of solution annealed 304L stainless steel and baffle bolts made of cold worked 316 stainless steel. These components undergo a large neutron flux at temperatures between 280 and $380^{\circ} \mathrm{C}$. This irradiation is known to induce a reduction of ductility and an overall hardening, i.e. an increase of the yield stress associated with the accumulation of the irradiation damage, mainly Frank dislocation loops, which act as obstacles to the motion of dislocations [1-5]. The radiation induced hardening is held responsible for the embrittlement of the materials and contributes to the stress corrosion cracking [6].

In view of its consequence on the evolution of the macroscopic properties (void swelling, creep, stress relaxation, loss of ductility and fracture toughness) the understanding of the microstructure evolution under irradiation is essential to predict time-of-life of internals. Thus, since the last 15 years a large number of studies have focused on the characterization of these microstructures under irradiation. A part of them covers the radiation induced segregation (RIS) at grain boundaries (GB), known to play a role in the loss of corrosion resistance and in the irradiation assisted stress corrosion cracking (IASCC) [7-14]. Transmission electron microscopy (TEM) observations have shown that radiation hardening

\footnotetext{
* Corresponding author. Tel.: +33 2329550 47; fax: +3323295 5032 .

E-mail address: philippe.pareige@univ-rouen.fr (P. Pareige).
}

could be caused by the formation of a high density of Frank loops (faulted loops with a Burgers vector $a_{0} / 3\langle 111\rangle$ lying in $\{111\}$ planes) and point defects clusters [15-20]. Recently, it was reported that saturation of hardening at high doses could be explained by the defaulting of Frank loops [15]. In addition to these observations, phase transformation or solute segregation inside grains or at grain boundaries are mentioned. Almost no precipitation is reported for irradiation temperature below $400{ }^{\circ} \mathrm{C}$. At least none is reported for 316 steel as referenced in [21]. Above $500^{\circ} \mathrm{C}, \mathrm{M}_{6} \mathrm{C}$ phases are observed. No intragranular precipitation is reported in 316 low fluence irradiated materials and temperature around $400^{\circ} \mathrm{C}$ [22]. In neutron fast reactor, $\gamma^{\prime}$ $\left(\mathrm{Ni}_{3} \mathrm{Si}\right)$ precipitates are mentioned even at $270^{\circ} \mathrm{C}$ and for high fluence $\left(>0.2 \times 10^{29} \mathrm{n} \mathrm{m}^{-2}\right)$. $\gamma^{\prime}$ precipitation or Ni-Si enrichment at Frank loops are reported in references [20-24]. Quantitative experimental results on the description of these (nano) structures are rare in the PWR ageing conditions (temperature and flux spectrum). However, it is important to understand the evolution of the microstructure under increasing fluence (evolution after 10$20 \mathrm{dpa}$ ) in order to predict in a realistic way the high fluence behaviour.

In the first part of this work a characterization, at the atomic scale, of a neutron-irradiated austenitic stainless steel (CW316) is given. Indeed, for the first time, chemical analyses using Laser Assisted Tomographic Atom Probe (LATAP) were performed on a bolt made of cold worked 316 austenitic stainless steel, extracted from the internal structures of a PWR after 17 years of reactor service. The irradiation temperature of these samples was $633 \mathrm{~K}$ and the 
irradiation dose was estimated to be $12 \mathrm{dpa}$. The result shows that neutron irradiation has a strong effect on the intragranular distribution of solute atoms. A very high number density $\left(6 \times 10^{23} \mathrm{~m}^{-3}\right)$ of $\mathrm{Ni}$ and Si-enriched and $\mathrm{Cr}$ and Fe-depleted "clusters' associated with Mo and $\mathrm{P}$ segregations at their interfaces was detected.

As reported in literature the need for basic information regarding the microstructural effects of ionizing particles has become important. Particle beams may be used in order to reproduce neutron damages (as proton [25]) or to realise ad'hoc experiments, using ions, to understand basic mechanisms of radiation induced or enhanced phenomena when displacement cascades are involved. In order to, first, try to reproduce the neutron irradiation effects on solute behaviour as seen above and, second, to study the behaviour of solute atoms submitted to point defects fluxes (with controlled parameters such as temperature, flux, fluence), microstructural characterisations of a CW $316 \mathrm{SS}$ irradiated with ions at a temperature of $350^{\circ} \mathrm{C}$ were performed. The second part of the document describes the procedure that has been used to analyse ion-irradiated CW 316SS with the Tomographic Atom Probe. Far from the neutron irradiation condition, the aim here is to try to reproduce the solute segregation/nanophase transformation associated to the point defects creation in the form of displacement cascades as function of dose and in a work in progress to be compared to TEM characterization and mean field simulation of point defect clusters (cluster dynamic).

Finally, each microstructural change (voids, grain boundary segregation, intragranular nanosegregation...) described in the literature or reported in this work is not able to lead to IASCC if taken separately $[8,26]$. Only a combination of these effects (due to the complex ageing condition (mechanic, irradiation, and environment)) leads to the undesirable IASCC. As internal structures and configuration as well as working condition of present reactor cores will not change, a way to try to mitigate the ageing of the material is to test new ones. Thus, in order to change the possible effects of point defects fluxes in CW 316SS, an ultrafine grained (UFG) CW 316 SS was elaborated by severe plastic deformation. The benefit of UFG 316SS, with grain size about $1-0.1 \mu \mathrm{m}$, has already been reported in the literature [27] when exposed to neutron irradiation. In our case, grain size is of the order of $40 \mathrm{~nm}$. Thus the extremely large surface fraction of grain boundaries must take part to the elimination of point defects, thus changing the structural evolution. A description of the elaboration method of the UFG CW 316 SS is given as well as first results on its behaviour under irradiation. It must be mentioned that these materials are also, for basic understanding, good candidates to study grain boundaries at the atomic scale. This paper will mainly report the nanoscale transformations that are experimentally observed under irradiation using the LATAP.

\section{Material and experimental}

The material investigated in this study is a 300 series stainless steel commonly used for core internals of PWR nuclear power plant namely a cold worked 316 used for baffle bolts. Its chemical composition is given in Table 1. It is $15 \%$ cold worked, fully austenitic, with a grain size about $40 \mu \mathrm{m}$. The microstructure contains numerous dislocations organized in cells and deformation twins.

All the samples for atom probe experiments were cut in the shape of extremely small size rods of $5 \mathrm{~mm}$ long and $0.1 \times$ $0.1 \mathrm{~mm}^{2}$ in the neutron-irradiated materials (prepared in hot cells at EDF Chinon Research Centre) to limit the level of radioactivity of the samples and $10 \mathrm{~mm}$ long and $0.3 \times 0.3 \mathrm{~mm}^{2}$ in cross section for the un-irradiated material. They were prepared as thin needle (end radius smaller than $50 \mathrm{~nm}$ ) by electropolishing, using a solution of $2 \%$ of perchloric acid diluted in 2-butoxyéthanol. Chemical characterization at the atomic scale was performed using LATAP developed in our laboratory (Groupe de Physique des Matériaux UMR CNRS 6634). The principle of this instrument is described in references $[28,29]$. Analyses of brittle materials, such as austenitic stainless steels are very difficult with conventional TAP (using electric pulses) because of the brittleness of the austenitic needles under the cyclic electrostatic stress. Now, with the use of laser pulses a large number of specimens are analysed and give reliable data sets. Analyses were performed at $80 \mathrm{~K}$, using femtosecond laser pulses with a pulse repetition rate equal to $2 \mathrm{kHz}$. The equivalent pulse fraction needs to range between $10 \%$ and $20 \%$ for reproducible and quantitative results.

\section{Study of neutron-irradiated material}

The neutron-irradiated specimens for atom probe examination were extracted from a cold worked 316 SS bolt coming from internals of a PWR reactor. Samples were removed at $40 \mathrm{~mm}$ from the head of the bolt. The irradiation temperature was estimated to be $633 \mathrm{~K}$. The neutron dose rate was $2.2 \times 10^{-8} \mathrm{dpa} \mathrm{s}^{-1}$ (dpa $^{-1}=\sigma \times \Phi$ where $\sigma=1500$ barn is the displacement cross section and $\Phi$ is the flux of neutrons with energy higher than $1 \mathrm{MeV})$ and the dose was about $12 \mathrm{dpa}\left(8 \times 10^{25} \mathrm{n} \mathrm{m}^{-2}\right)$. TEM microstructural examinations on different parts of this bolt [30,31] show interstitial Frank loops and small 'black dots'. The number density and the diameter of Frank loops and black dots were not measured for this dpa level and exact location of extraction of atom probe samples. Most of the initial dislocation structure resulting from the cold working of the bolt has disappeared after irradiation. No precipitation is observed (at TEM resolution). A few cavities/bubbles are observed with a number density of $2.3 \times 10^{21} \mathrm{~m}^{-3}$. Their diameter is about $10 \mathrm{~nm}$. In order to isolate the effect of neutron irradiation, un-irradiated CW 316 SS samples were also investigated. These specimens were obtained from

Table 1

Bulk composition of the 316SS used to manufacture the bolt (Bolt in table), bulk composition of the reference un-irradiated sample grade (Ref. in the table), matrix compositions (at.\%) measured by LATAP in un-irradiated samples (matrix un-irradiated) and in the neutron-irradiated bolt (12 dpa). The errors are given by the standard deviation $2 \sigma$. Balance is iron. Values are given both in atomic (with weight percents for Ref. and Bolt). n.s.: not significant.

\begin{tabular}{|c|c|c|c|c|c|c|c|c|c|c|c|c|}
\hline & & $\mathrm{C}$ & $\mathrm{P}$ & $S$ & $\mathrm{Si}$ & $\mathrm{Cr}$ & $\mathrm{Ni}$ & $\mathrm{Mn}$ & Co & Mo & $\mathrm{Cu}$ & $\mathrm{V}$ \\
\hline \multirow[t]{2}{*}{ Ref. } & $w t \%$ & 0.054 & 0.027 & 0.022 & 0.68 & 16.60 & 10.60 & 1.12 & 0.12 & 2.25 & 0.24 & - \\
\hline & at.\% & 0.25 & 0.048 & 0.038 & 1.34 & 17.70 & 10.02 & 1.13 & 0.11 & 1.30 & 0.21 & - \\
\hline \multirow[t]{2}{*}{ Bolt } & $w t \%$ & 0.026 & 0.017 & 0.016 & 0.64 & 16.80 & 12.10 & 1.80 & $<0.05$ & 2.56 & 0.10 & - \\
\hline & at.\% & 0.120 & 0.030 & 0.028 & 1.27 & 17.92 & 11.44 & 1.82 & $<0.05$ & 1.48 & 0.09 & - \\
\hline \multirow[t]{2}{*}{ Matrix un-irradiated } & at.\% & 0.27 & 0.02 & n.s. & 1.57 & 18.9 & 8.5 & 1.19 & 0.14 & 0.9 & 0.13 & 0.06 \\
\hline & $2 \sigma$ & 0.03 & 0.01 & - & 0.07 & 0.2 & 0.2 & 0.06 & 0.02 & 0.07 & 0.02 & 0.01 \\
\hline \multirow[t]{2}{*}{ Matrix neutron irradiated } & at.\% & 0.08 & 0.03 & n.s. & 0.68 & 20.8 & 9.9 & 2.2 & 0.24 & 1.30 & 0.10 & 0.13 \\
\hline & $2 \sigma$ & 0.02 & 0.01 & - & 0.05 & 0.2 & 0.2 & 0.1 & 0.03 & 0.07 & 0.02 & 0.02 \\
\hline
\end{tabular}


another heat of CW 316 SS. Its bulk composition is also given in Table 1 . Analyses of the un-irradiated sample show a homogeneous distribution of solute atoms confirmed by statistical tests on distribution of atomic positions. Thus, the mean composition of the analysed volumes is representative of the austenite composition (Table 1). The reported values in Table 1 show a good agreement between the measured concentrations and the bulk composition.

As far as matrix composition of irradiated samples (Table 1) is concerned, Si depletion and $\mathrm{Cr}$ enrichments are noticeable. This is due to the formation, in the bulk after irradiation, of $\mathrm{Ni}$ and $\mathrm{Si}$ enriched clusters. These clusters are clearly visible in the 3D reconstruction (Fig. 1) and are plainly $\mathrm{Ni}$ and Si-enriched. Their number density is $6 \pm 3 \times 10^{23} \mathrm{~m}^{-3}$.

The composition of these clusters is given in Table 2 . The average $\mathrm{Si}$ concentration is 40 at.\% while $\mathrm{Ni}$ concentration reaches 50 at.\% (Fig. 2). On the contrary, $\mathrm{Fe}$ and $\mathrm{Cr}$ concentration decrease down to 5 and 2 at.\% respectively. Fig. 2 also reveals co-segregation of $\mathrm{P}$ and $\mathrm{Mo}$, non-homogeneously distributed at the cluster interface.

The mean characteristic of the lenticular shape of the cluster population is: $6 \mathrm{~nm}$ in diameter and $4 \mathrm{~nm}$ in thickness in the centre. The precipitated volume fraction is estimated to be $7 \%$. The same value is found either the calculation is based on mass balance (taking into account the reported composition of phases, with $\mathrm{Ni}$ and $\mathrm{Si}$ for example) or with number density and size of clusters. A detailed description of these data may be seen in reference [30]. As reported in Ref. [30], the similarity between the number density and size of $\mathrm{Ni}-\mathrm{Si}$ clusters measured in this work and the number density and size of interstitial dislocation loops observed by TEM in the already referenced literature (i.e. Frank loop number density of the order of: $10^{23} \mathrm{~m}^{-3}$ and diameter of $9 \pm 2 \mathrm{~nm}$ ) strongly supports the radiation induced segregation mechanism of $\mathrm{Ni}$ and $\mathrm{Si}$ solutes towards dislocation loops as already reported in $[20,24,31]$. Further investigations on materials irradiated to

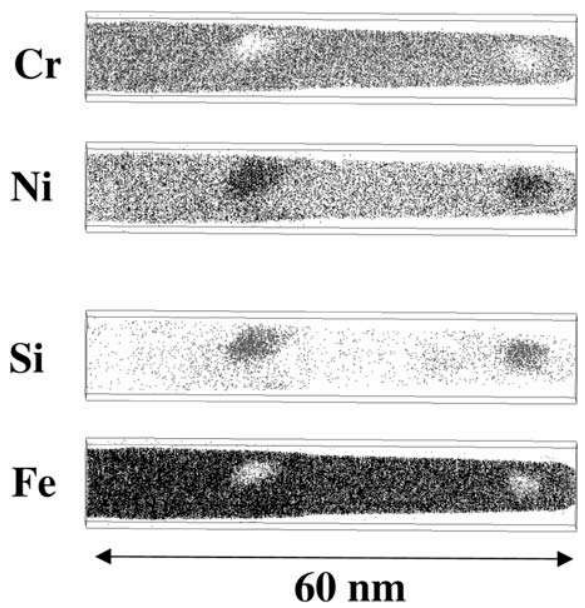

Fig. 1. 3D reconstruction of a volume of un-irradiated CW $3165 S$ analysed by LATAP. $\mathrm{Cr}, \mathrm{Ni}, \mathrm{Si}$, and Fe are represented. The volume is $10.4 \times 10.4 \times 60 \mathrm{~nm}^{3}$.

Table 2

Chemical composition of $\mathrm{Ni}$ and Si-enriched clusters observed in the irradiated sample. The enrichment factor $F$ is given by the ratio of the concentration in the feature over the matrix concentration. Balance is iron.

\begin{tabular}{lllllll}
\hline & & $\mathrm{P}$ & $\mathrm{Si}$ & $\mathrm{Cr}$ & $\mathrm{Ni}$ & $\mathrm{Mo}$ \\
\hline Ni and Si -enriched clusters & at.\% & 0.7 & 38.1 & 1.2 & 53.9 & 0.4 \\
& $2 \sigma$ & 0.5 & 2.8 & 0.6 & 2.9 & 0.4 \\
& $F$ & 23 & 56 & 0.06 & 5.4 & 0.3 \\
\hline
\end{tabular}

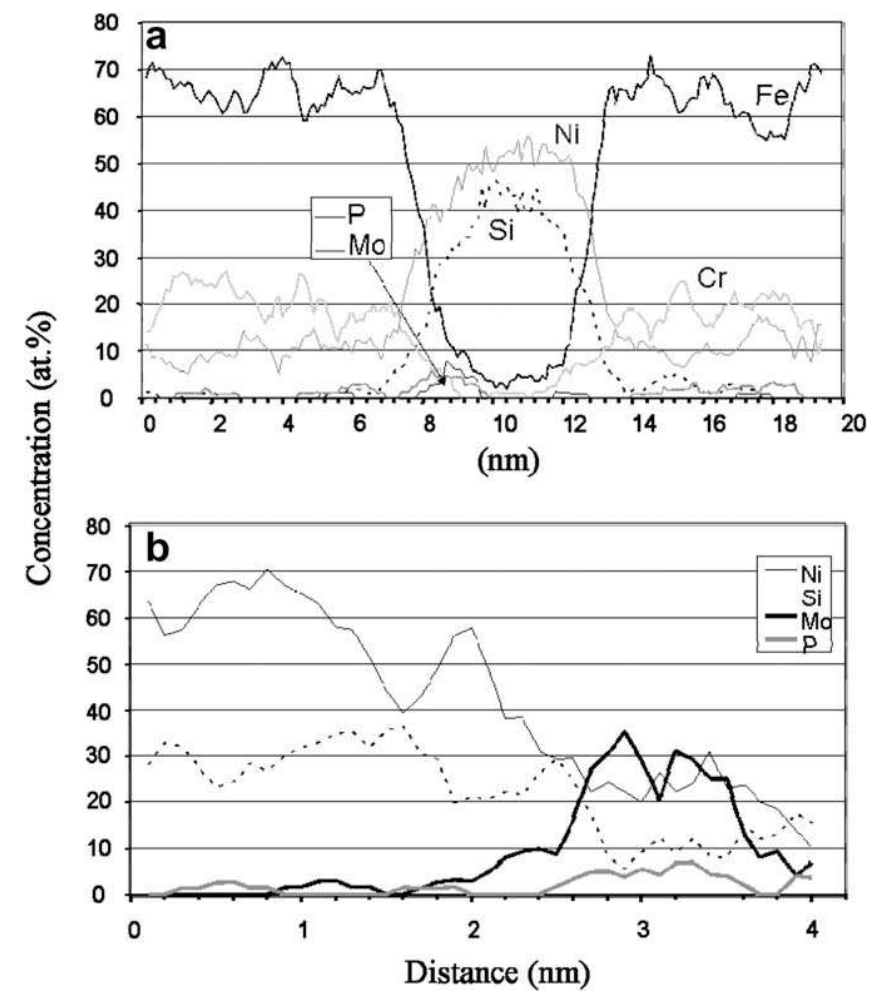

Fig. 2. (a) Concentration profile along a cluster. $\mathrm{Fe}, \mathrm{Ni}, \mathrm{Cr}, \mathrm{Si}, \mathrm{Mo}$ and $\mathrm{P}$ are represented. (b) Zoom of the P and Mo segregation (left part profile (a)).

higher fluence are planned. Also, irradiation with ions combined with TAP characterization and simulations, are needed and in progress to validate these hypotheses.

\section{Study of ion-irradiated material}

First results on ion irradiation in atom probe samples are reported in this part. The aim of the experiment is to produce irradiation defects through displacement cascades, as in the real process of neutron irradiation. In PWR internal structures, primary knocked atoms are produced by energetic neutrons $(>1 \mathrm{MeV})$ homogeneously in the bulk. The incident ion beam for the ion irradiation experiment exhibits an energy distribution close to $\sim 100 \mathrm{keV}$ and is unable to penetrate the bulk material to a depth larger than some tens of nanometers. The particular shape of samples ( $100 \mathrm{~nm}$ thick) for atom probe analysis is particularly adequate. Thus the effects of displacements cascades on the microstructure may be observed directly after analysing the specimen with LATAP. SRIM simulation [32] gives the distribution of defects in the depth of a chosen material caused by the interaction with a given ion beam. So, for a given defect production or fluence and a given flux (and temperature), it is possible to estimate the incident ion energy needed to produce randomly distributed cascades in the average depth $(\sim 50 \mathrm{~nm})$ of a needle-shaped specimen. Parameters under control are temperature, irradiation time and flux, primary ion energy and alloy composition. It must be kept in mind that the method used here to produce defects in commercial alloys presents characteristics that are different from actual neutron irradiation. In commercial stainless steel, the actual neutrons flux is close to $10^{-8} \mathrm{dpa} \mathrm{s}^{-1}$, while the ion irradiation reaches a flux close to $5 \cdot 10^{-4} \mathrm{dpa} \mathrm{s}^{-1}$.

CW 316 SS atom probe samples have been prepared and irradiated, at two different doses ( 1 and $5 \mathrm{dpa}$ ), with $160 \mathrm{keV} \mathrm{Fe}^{+}$ions at CSNSM Orsay on IRMA accelerator (experimental details may be 
Table 3

Irradiation conditions at CSNSM Orsay (dpa are calculated using Kinchin-Pease formalism in SRIM)

\begin{tabular}{llll}
\hline Dose (dpa) & Dose $\left(\right.$ ions $\left.\mathrm{m}^{-2}\right)$ & Dose rate $\left(\right.$ ions $\left.\mathrm{m}^{-2} \mathrm{~s}^{-1}\right)$ & Irradiation time $(\mathrm{s})$ \\
\hline 1 & $5.5 \times 10^{18}$ & $6.25 \times 10^{14}$ & 8700 \\
5 & $2.7 \times 10^{19}$ & $1.56 \times 10^{15}$ & 17400 \\
\hline
\end{tabular}

found in $[31,33])$. The irradiation temperature was $350{ }^{\circ} \mathrm{C}$ close to the temperature of the above neutron irradiation. Irradiation conditions are given in Table 3.

Analyses of the samples irradiated to $1 \mathrm{dpa}$ reveal Si concentration fluctuations in the austenitic matrix (Fig. 3). These Si concentration fluctuations are confirmed using statistical tests between spatial distribution of solute atoms in un-irradiated and irradiated materials; after ion irradiation to $1 \mathrm{dpa} \mathrm{Si}$ is no more randomly distributed. The size of the Si-enriched segregation is in the range of 1-2 $\mathrm{nm}$. The local Si concentration reaches about $7 \%$ while the average silicon level in the matrix is 1.3 at.\% (significant enrichment factor of about 5).

After ion irradiation up to $5 \mathrm{dpa}$, the presence of a high number density $\left(1.4 \times 10^{23} \mathrm{~m}^{-3}\right)$ of Si-enriched clusters is observed (as revealed in Fig. 4). Their size is in the range of $2-5 \mathrm{~nm}$. There average composition is (in at.\%): $8 \pm 1 \mathrm{Si}, 14.5 \pm 2 \mathrm{Cr}, 0.6 \pm 0,4 \mathrm{Mn}, 14 \pm 2 \mathrm{Ni}$ and $63 \pm 3 \mathrm{Fe}$ (matrix composition is determined as: $1.7 \pm 0.04 \mathrm{Si}$, $18 \pm 0.1 \mathrm{Cr}, 1.28 \pm 0.03 \mathrm{Mn}, 10.1 \pm 0.1 \mathrm{Ni}$ and $67.2 \pm 0.1 \mathrm{Fe}$ ). It appears that the clusters are now also slightly enriched in $\mathrm{Ni}$ and depleted in $\mathrm{Cr}$ and $\mathrm{Fe}$, as observed in the bigger clusters initiated by the neutron irradiation.

The Si concentration fluctuations observed after irradiation up to $1 \mathrm{dpa}$ could be the first step of the formation of Si-enriched precipitates observed at $5 \mathrm{dpa}$. It must be noted here that $\mathrm{Si}$ is mainly coupled with interstitial fluxes, which migrate much faster than

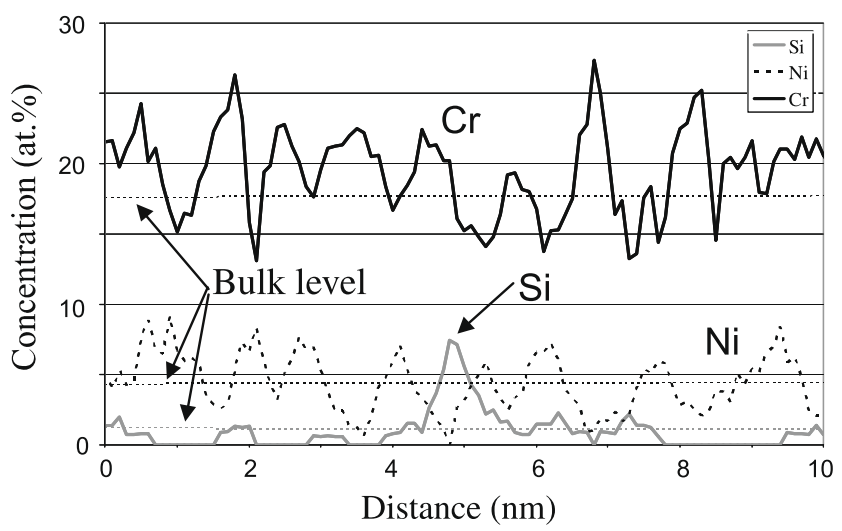

Fig. 3. Concentration profile along a volume of $316 \mathrm{SS}$ irradiated at $1 \mathrm{dpa}$. $\mathrm{Ni}, \mathrm{Cr}$ and $\mathrm{Si}$ concentrations are represented. A Si concentration fluctuation is visible (black arrow)

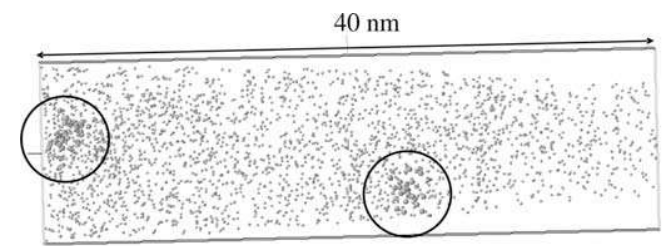

Fig. 4. 3D reconstruction of a volume of 316 SS ion irradiated to $5 \mathrm{dpa}$ analysed Only $\mathrm{Si}$ is represented. Thick atoms into black circles correspond to Si clusters ( $\mathrm{Si}$ concentration $>4$ at.\%). vacancies (associated to $\mathrm{Ni}$ diffusion). This solute segregation may be strongly associated to interstitial loops. These segregations must be identical or early stage of the $\mathrm{Ni}$ and Si-enriched clusters observed after neutron irradiation. These first results show that ion may reproduce structural changes observed under neutron irradiation. More experiments with larger doses and different dose rates and temperatures, associated to TEM experiments and mean field cluster dynamic simulation (to simulate point defects evolution) are in progress to determine the kinetic and mechanism of formation of the clusters. This will enable to give prediction of the evolution of the microstructure to higher fluence.

\section{Study of nanostructured ion-irradiated material}

Radiation-Induced Segregation in austenitic stainless steels has been widely studied because of its assumed contribution to IASCC in PWR core components. RIS is due to a permanent flux of point defects produced by irradiation, as interstitials and vacancies, towards sinks like dislocation loops or grain boundaries. Due to the coupling between point defects and solutes fluxes, a solute segregation towards sinks and more particularly to grain boundaries is induced. This change of composition at grain boundaries is one of the reasons of IASCC. Although studies show that segregation alone cannot explain IASCC, it is important to characterize solute segregations at grain boundaries. Currently, Auger electron Spectroscopy (AES) and Scanning Transmission Electron Microscopy using Energy-Dispersive X-ray Spectroscopy (STEM-EDS) are the main methods to quantify grain boundary composition [8]. Both techniques give satisfactory results but, due to their spatial resolution, are often difficult to compare to numerical simulation (atomic scale simulation for example). One of the most appropriated techniques to explore matter at atomic scale is the atom probe. Thus, one aim of this work is to analyse irradiated grain boundaries using this atomic resolution technique. Taking into consideration, in one hand, the analysed volume using an atom probe, about $10 \times 10 \times 100 \mathrm{~nm}^{3}$ for conventional atom probe and 25 times more for a wide angle atom probe, and, in the other hand, the grain size in austenitic SS (about $40 \mu \mathrm{m}$ ), the probability of grain boundary interception per analysis is quite small (less than $1 \%$ ). In order to increase this probability, the grain size of a CW316 SS has been reduced by severe plastic deformation (SPD) down to $40 \mathrm{~nm}$ using High Pressure Torsion (HPT) [34-36] at the Institute of Physics of Advanced Materials in Ufa (Russia). The principle of HPT is given in Fig. 5(a). In this work, the number of turns was equal to 5 under a pressure of $5 \mathrm{GPa}$. The deformation occurred at room temperature. TEM samples have been prepared at the periphery of HPT
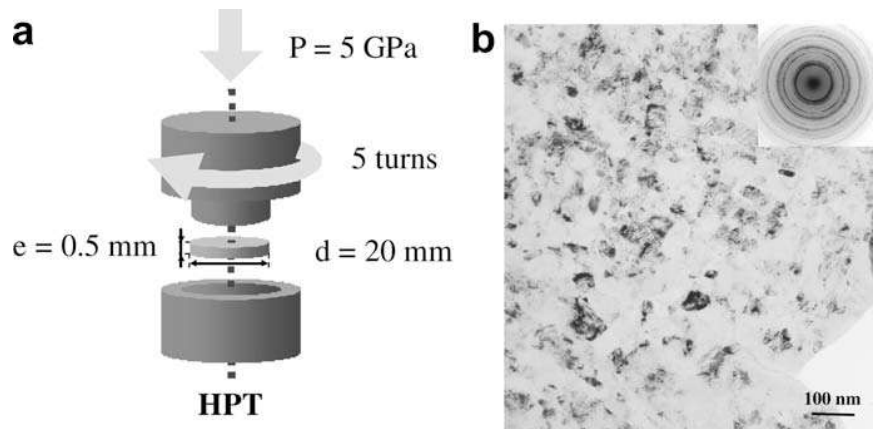

Fig. 5. (a) Schematic illustration of the HPT processing. Samples are prepared under the shape of plates of $20 \mathrm{~mm}$ in diameter and $0.5 \mathrm{~mm}$ in thickness. They are deformed at room temperature by HPT under a 5 GPa hydrostatic pressure. Number of turns was equal to 5 which correspond to a strain shear about 1250 at the periphery of the plates. (b) TEM micrograph showing the microstructure of CW 316 SS after severe plastic deformation. 
disks. The microstructure observed is shown in Fig. 5(b) and clearly reveals the extremely small size of the grains.

Rods for atom probe of $10 \mathrm{~mm}$ long and $0.3 \times 0.3 \mathrm{~mm}^{2}$ in section were cut into nanostructured disks and irradiated with $160 \mathrm{keV} \mathrm{Fe}$ at $350{ }^{\circ} \mathrm{C}$ at the laboratory PHYMAT in Poitiers (France). The dose rate was $2.9 \times 10^{15}$ ions $\mathrm{m}^{-2} \mathrm{~s}^{-1}$ and the dose was $5.2 \times 10^{19}$ ions $\mathrm{m}^{-2}$. The dose in displacement per atoms is, calculated by using the Kinchin-Pease formalism in SRIM [32], estimated to be $10 \mathrm{dpa}$. It must be noted that due to the small size of the atom probe sample a part of the point defects must be eliminated at the specimen surface (point defects and may be point defects clusters due to the image force). However, in this work, nanostructured materials as well as large grain materials have been irradiated in same conditions. The comparison between both materials will clearly reveals the effect of grain size.

Chemical characterization was performed using LATAP on unirradiated nanostructured samples and ion-irradiated nanostructured samples. Two samples of the un-irradiated nanostructured CW 316 SS have been analysed. Taking into account the overall analysed volumes, at least five grain boundaries should have been intercepted. Fig. 6 shows the P, Ni and Si distribution. No Ni or Sidepleted zone (signature of a grain boundary) is detected. Only $\mathrm{P}$ segregation is detected, that could be attributed to the presence of segregation on a boundary. This indicates that in the as-processed un-irradiated nanostructured specimen, the grain boundary composition is probably the same as the austenitic matrix one. This is different from what is reported in literature [37,38], with the presence of an equilibrium chromium enrichment in un-irradiated stainless steels due to the low surface tension of $\mathrm{Cr}$ compared to $\mathrm{Ni}$ and $\mathrm{Si}$ and the strong ordering tendency between $\mathrm{Ni}$ and $\mathrm{Cr}$. This is due to the fact that no diffusion has occurred during the severe deformation (performed at room temperature) and segregation profiles in nanostructured materials are not equilibrium profiles.

On the contrary, in ion-irradiated specimens, grain boundaries are clearly visible thanks to the high segregation of $\mathrm{Si}$ and $\mathrm{Ni}$ (Fig. 7). The measurements show an enrichment in Si up to 4 at.\%. At the same time, the $\mathrm{Ni}$ concentration reaches 18 at.\% and the $\mathrm{Cr}$ concentration decreases to 14 at.\%. Some $\mathrm{C}$ and $\mathrm{P}$ segregation could also be observed (up to 2 at.\% for C). The width of these grain boundaries segregations is $2 \mathrm{~nm}$.

The amount of chromium and nickel segregated in these nanostructured CW 316 SS are compared with results from the literature on 316 SS and $\mathrm{Fe}-20 \mathrm{Cr}-9 \mathrm{Ni}$ irradiated with protons or

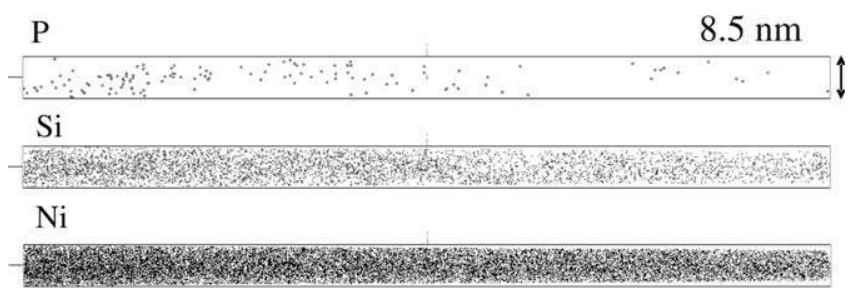

Fig. 6. 3D reconstruction of a volume of non-irradiated nanostructured CW 316 SS analysed with LATAP. P, Si and $\mathrm{Ni}$ are represented.

$10 \mathrm{~nm}$

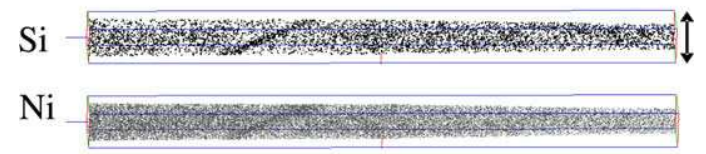

Fig. 7. 3D reconstruction of a volume of ion-irradiated nanostructured CW 316 SS analysed with LATAP. Si and Ni are represented. A grain boundary is clearly visible.

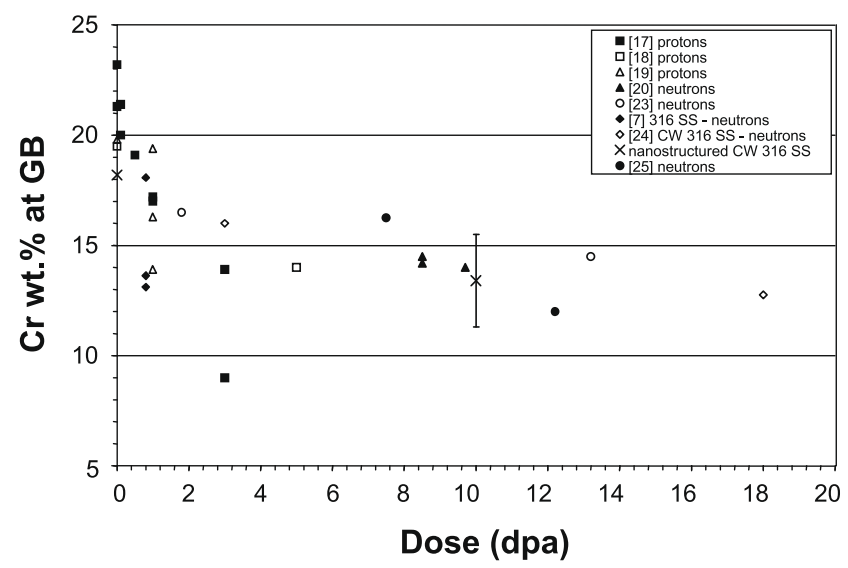

Fig. 8. Comparison of grain boundary chromium composition as a function of dose for ion-irradiated nanostructured 316 SS with proton and neutron-irradiated 316 SS from the literature.

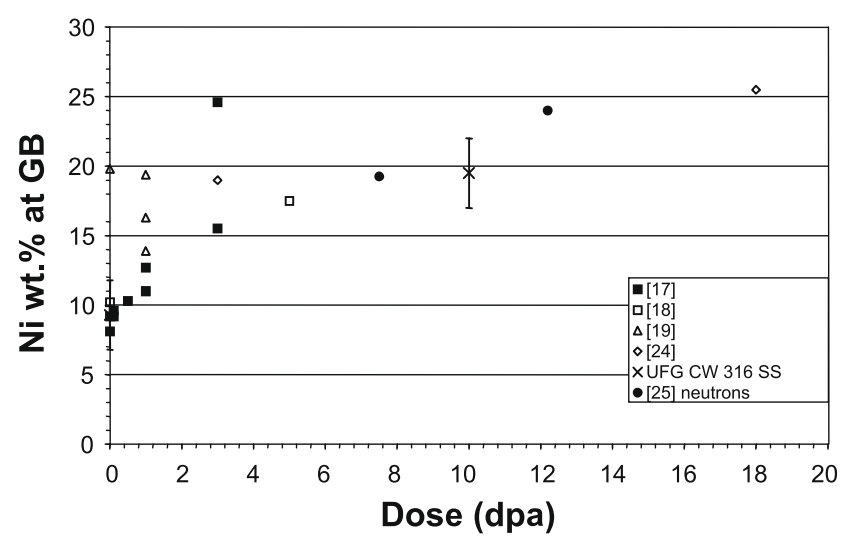

Fig. 9. Comparison of grain boundary composition nickel composition as a function of dose for ion-irradiated nanostructured 316 SS with proton and neutronirradiated 316 SS from the literature.

neutrons [7,11,23,25,39,40,42,43] (Figs. 8 and 9). The chromium and nickel segregation in nanostructured CW 316 SS agree very well with neutron and proton data. Concerning the silicon segregation, several studies show silicon enrichment at grain boundaries $[7,25,41,44]$. In most cases, the degree of silicon segregation is between 3 and 5 according to the irradiation dose. In our case, the silicon concentration is multiplied by about 3.5. This is consistent with previous results.

These preliminary results are encouraging for the study of grain boundary segregation. These nanomaterials give us the possibility to study many segregation areas and to easily play with the irradiation conditions (controlled flux, temperature,) during ion irradiation. As far as intragranular distribution of solutes is concerned, no solute enrichment or depletion was observed inside the grains (as observed under neutron and ion in the previous paragraphs). This absence of $\mathrm{Ni}$ and Si-enriched clusters may indicate that no Frank loops are formed within the nanograins [45].

In parallel to this fundamental work, the overall properties of this new UFG CW 316SS are tested to be compared to the standard CW 316SS.

\section{Conclusion}

An atomic scale characterization of CW 316SS was performed using the Laser Assisted Tomographic Atom Probe (LATAP). This 
new generation of atom probe allows austenitic steels to be easily analysed using this technique. Application of LATAP was done for the first time on a neutron-irradiated CW 316SS coming from internals of a PWR reactor. $\mathrm{Ni}$ and Si-enriched clusters were detected in the austenitic matrix. These clusters are suggested to be associated to Frank loops. The ion irradiation of atom probe samples reveals that these $\mathrm{Ni}$ and Si-enriched clusters may be reproduced. Study at different fluences ( 1 and $5 \mathrm{dpa}$ ) shows that $\mathrm{Si}$ is first segregated and joint later with Ni. Finally, ultrafine grained CW 316 SS were processed by severe plastic deformation (HPT: High Pressure Torsion). The grain size is reduced down to $40 \mathrm{~nm}$. The ion irradiation of this UFG material allows a large amount of grain boundaries to be study. The $\mathrm{Cr}$ depletion and $\mathrm{Si}$ and $\mathrm{Ni}$ enrichments observed, for a given dpa level, are representative of what is measured in neutron or proton irradiated materials. Also the $\mathrm{Ni}$ and $\mathrm{Si}$-enriched clusters are not detected within the grains. These materials are good candidates for fundamental studies of grain boundaries submitted to irradiation. Understanding of the RIS effects in this UFG CW 316SS may help for long term prediction of the evolution of standard CW 316SS.

\section{Acknowledgements}

The authors thank Professor Ruslan Valiev for the preparation of the nanostructured material at the Institute of Physics of Advanced Materials in Ufa (Russia). We are grateful to Michel Drouet for performing the ion irradiation at the PHYMAT laboratory (UMR 6630) at Poitiers (France) and Odile Kaitasov for ion irradiation at the CSNSM laboratory at Orsay (France). We gratefully acknowledge Jean-Paul Massoud and Cedrik Pokor from EDF R\&D Les Renardières and Chinon (France) for supplying the neutron irradiated and reference material CW 3165 S and fruitful discussion. The TEM investigations of nano-grained materials were supported by the IP3 project of the Sixth Framework Programme of the European Commission: ESTEEM-Contract No. 026019.

\section{Reference}

[1] ML. Grossbeck, PJ. Maziasz, AJ. Rowcliffe, J. Nucl. Mater. 191 (1992) 808

[2] GR. Odette, D. Frey, J. Nucl. Mater. 85 (1979) 817.

[3] F. Garner, M.L. Hamilton, N.F. Panayotou, G.D. Johnson, J. Nucl. Mater. 103 (1981) 803.

[4] N. Yoshida, HL. Heinisch, T. Muroga, K. Araki, M. Kiritani, J. Nucl. Mater. 179 (1991) 1078

[5] P.B. Hirsch, in: R.E. Smallman, J.E. Harris (Eds.), in: Vacancies'76, 1976

[6] P. Scott, J. Nucl. Mater. 211 (1994) 101

[7] J.F. Williams, T.R. Mager, P. Spellward, J. Walmsley, M. Koyama, I. Suzuki, H. Mimaki, in: Eighth International Symposium on Environmental Degradation of Materials in Nuclear Power Systems - Water Reactors, Amelia Island, FL, USA 10-14 August 1997, p. 725

[8] J.T. Busby, G.S. Was, E.A. Kenik, J. Nucl. Mater. 302 (2002) 20.

[9] S.M. Bruemmer, E.P. Simonen, P.M. Scottn, P.L. Andresen, G.S. Was, J.L. Nelson, J. Nucl. Mater. 274 (1999) 299.
[10] S.M. Bruemmer, L.A. Charlot, E.P. Simpson, in: D. Cubicciotti, E.P. Simonen, R. Gold (Eds.), Proceedings of the Fifth International Symposium on Environmental Degradation of Materials in Nuclear Power Systems - Water Reactors, American Nuclear Society, La Grange Park, IL, 1992, p. 821.

[11] K. Fukuya, M. Nakano, K. Fujii, T. Torimaru, J. Nucl. Sci. Technol. 41 (2004) 594

[12] G.S. Was, P.L. Andresen, J. Metals 44 (1992) 8

[13] G.S. Was, S.M. Bruemmer, J. Nucl. Mater. 216 (1994) 326

[14] P.L. Andresen, F.P. Ford, S.M. Murphy, J.M. Perks, in: Proceedings of the Fourth International Symposium on Environmental Degradation of Materials in Nuclear Power Systems - Water Reactors, Jekyll Island, GA, 1989, p. 1

[15] C. Pokor, Y. Brechet, P. Dubuisson, J.-P. Massoud, X. Averty, J. Nucl. Mater. 326 (2004) 30.

[16] S. Zinkle, P. Maziasz, R. Stoller, J. Nucl. Mater. 206 (1993) 266

[17] J. Gan, G.S. Was, J. Nucl. Mater. 297 (2001) 161.

[18] B.H. Sencer, G.M. Bond, M.L. Hamilton, F.A. Garner, S.A. Maloy, W.F. Sommer, J. Nucl. Mater. 296 (2001) 112.

[19] N. Hashimoto, E. Wakai, J.P. Robertson, J. Nucl. Mater. 273 (1999) 95

[20] D.J. Edwards, E.P. Simonen, S.M. Bruemmer, J. Nucl. Mater. 317 (2003) 13.

[21] S. Hamada, M. Suzuki, P.J. Maziasz, A. Hishinuma, M.P. Tanaka, in: Fourteenth International Symposium, ASTM STP 1046, vol. 1, 1989, p. 172.

[22] S. Bruemmer, J. Nucl. Mater. 274 (1999) 299.

[23] D.J. Edwards, E.P. Simonen, F.A. Garner, L.R. Greenwood, B.M. Oliver, S.M Bruemmer, J. Nucl. Mater. 317 (2003) 32.

[24] E.A. Kenik, K. Hojou, J. Nucl. Mater. 191-194 (1992) 1331.

[25] G. Was, J. Busby, T. Allen, E. Kenik, A. Jenssen, S. Bruemmer, J. Gan, A. Edwards, P. Scott, P. Andresen, J. Nucl. Mater. 300 (2002) 198

[26] K. Fukuya, M. Nakano, K. Fujii, T. Torimaru, J. Nucl. Sci. Technol. 41-5 (2004) 594.

[27] H. Matsuoka, T. Yamasaki, Y. Zheng, T. Mitamura, M. Terasawa, T. Fukami, Mater. Sci. Eng. A 449-451 (2007) 790

[28] D. Blavette, A. Bostel, J.M. Sarrau, B. Deconihout, A. Menand, Nature 363 (1993).

[29] B. Gault, F. Vurpillot, A. Vella, M. Gilbert, A. Menand, D. Blavette, B. Deconihout, Rev. Sci. Instrum. 77 (2006) 043705

[30] A. Etienne, B. Radiguet, P. Pareige, J.-P. Massoud, C. Pokor, J. Nucl. Mater. 382 (2008) 64.

[31] C. Pokor, J.-P. Massoud, P. Pareige, J. Garnier, D. Loisnard, P. Dubuisson, B. Doisneau, Y. Brechet, in: Twelfth International Conference on Environmental Degradation of Materials in Nuclear Systems - Water Reactors, The Minerals, Metals and Materials Society, Salt Lake City, 2005.

[32] J.F. Ziegler, J.P. Biersack, U. Littmark, The Stopping and Range of Ions in Solids, Pergamon Press, New York, 1985.

[33] R. Krummeich, P. Pareige, JP. Massoud, S. Jumel, Surf. Interface Anal. 36 (2004) 575

[34] R.Z. Valiev (Ed.), Ann. Chim. Fr. 21 (6-7) (1996) 369.

[35] R.Z. Valiev, A.V. Korznikov, R.R. Mulyukov, Mater. Sci. Eng. A168 (1993) 141.

[36] I.V. Alexandrov, R.Z. Valiev, Scr. Mater. 44 (2001) 1605.

[37] M. Nastar, Philos. Mag. 85 (4-7) (2005) 641.

[38] J.T. Busby, G.S. Was, S.M. Bruemmer, D.J. Edwards, E.A. Kenik, Mater. Res. Soc Symp. Proc. 540 (1999) 451

[39] T.R. Allen, J.T. Busby, G.S. Was, E.A. Kenik, J. Nucl. Mater. 255 (1998) 44.

[40] G.S. Was, T.R. Allen, J.T. Busby, J. Gan, D. Damcott, D. Carter, M. Atzmon, E.A. Kenik, J. Nucl. Mater. 270 (1999) 96.

[41] R.D. Carter, D.L. Damcott, M. Atzmon, G.S. Was, J. Nucl. Mater. 211 (1994) 70

[42] K. Asano, K. Fukuya, K. Nakata, M. Kodoma, in: D. Cubicciotti, (Ed.), Proceedings of the Fifth International Symposium on Environmental Degradation of Materials in Nuclear Power Systems Water Reactors, Monterey, CA American Nuclear Society, La Grange Park, IL, 1992, p. 838.

[43] J. Walmsley, B.P. Spellward, S. Fisher, A. Jenssen, in: R.E. Gold, E.P. Simonen (Eds.), Proceedings of the Seventh International Symposium on Environmental Degradation of Materials in Nuclear Power Systems Water Reactors, NACE International, Houston, TX, 1995, p. 985.

[44] S.M. Bruemmer, T.F. Soran, J.I. Cole, B.W. Arey, L.A. Charlot, C.F. Windisch Jr., in: Corrosion/95, Nace, paper No. 420

[45] B. Radiguet, A. Etienne, P. Pareige, X. Sauvage, R. Valiev, J. Mater. Sci., in press, doi $10.1007 / \mathrm{s} 10853-008-2875-8$. 